\title{
Интродукция представителей рода Hemerocallis L. в коллекции ботанического сада Саратовского государственного университета
}

\section{Introduction of representatives of the genus Hemerocallis $\mathbf{L}$. in the collection of Botanical Garden of Saratov State University}

\author{
Шакина Т. Н., Куликова Л. В., Петрова Н. А. \\ Shakina T. N., Kulikova L. V., Petrova N. A. \\ Саратовский государственный университет им. Н. Г. Черныпевского УНЦ «Ботанический сад», г. Саратов, Россия. \\ E-mail:shakinatn@mail.ru; kulikovaluda064@mail.ru; Nasch-1@yandex.ru
}

The Educational Centre "Botanical Garden" of Saratov State university n. a. N. G. Shernyshevsky, Saratov, Russia

\begin{abstract}
Peфepam. В статье представлены результаты изучения феноритмов и интродукционной оценки трех видов Hemerocallis citrina Baroni, H. fulva (L.) L., H. lilio-asphodelus L. и 15-ти сортов лилейника гибридного (H. hybri$d a \times$ hort.): 'Carry Queen', 'Date Book', 'Regal Air', 'Sabina Bauer', 'Глория', 'Americane Revolution', 'Grand Palase', 'Nigrette', 'Prairie Blue Eyes', 'Luxury Lice', 'Cara Mia', 'Tejas', 'Winnie-The-Pooh', 'Night Beacon', 'Theresa Hall'. B ходе фенологических наблюдений в период с 2010 по 2018 гг. в УНЦ «Ботанический сад» СГУ г. Саратова были установлены календарные даты основных фаз развития, определены средние значения сроков и продолжительность цветения у изученных видов и сортов. Проведенное исследование показало, что изученные образцы устойчивы в культуре, так как они зимостойкие, невосприимчивые к болезням и вредителям, отличаются декоративностью цветения. Сорта лилейника гибридного адаптировались и в течение ряда лет успешно произрастают, не потеряв своих сортовых особенностей. Оценка успешности интродукции показала, что изученные виды и сорта лилейников оказались очень перспективными для введения в культуру и могут быть рекомендованы для озеленения в условиях г. Саратова. Использование изученных видов и сортов лилейника разных сроков цветения расширяет возможности их применения в ландшафтном дизайне и создания композиций непрерывного цветения.
\end{abstract}

Ключевые слова. Интродукция, лилейник, Саратовское Поволжье, фенологические фазы.

Summary. The article presents the results of the study of phenorhythms and the introduction assessment of three species Hemerocallis citrina Baroni, $H$. fulva (L.) L., H. lilio-asphodelus L. and 15 varieties of daylily hybrid (H. hybrida $\times$ hort.): 'Carry Queen', 'Date Book', 'Regal Air', 'Sabina Bauer', 'Gloria', 'Americane Revolution', 'Grand Palase', 'Nigrette', 'Prairie Blue Eyes', 'Luxury Lice', 'Cara Mia', 'Tejas', 'Winnie-The-Pooh', 'Night Beacon', 'Theresa Hall'. During the phenological observations 2010-2018 years in the Educational Centre "Botanical Garden" SSU of Saratov, the calendar dates of the main development phases were established, the average values of terms and duration of flowering for the studied species and varieties were determined. This investigation showed that the studied samples are stable in culture, as they are winterhardy, resistant to diseases and pests, are noted for decorative flowering. The varieties of the daylily hybrid have adapted and have been successfully growing for a number of years without losing their varietal characteristics. Evaluation of the introduction success showed that the studied species and varieties of daylilies turned out to be prospective for introduction into culture and can be recommended for landscaping in the conditions of the city of Saratov. The use of the daylily's studied species and varieties of different periods of flowering expands the possibilities of their use in landscape design and the creation of compositions of continuous flowering.

Key words. Daylily, introduction, phenological phases, Saratov Volga region.

Род гемерокаллис, или лилейник (Hemerocallis L.), из семейства гемерокаллисовых (Hemerocallidaceae R. Br.), включает 18 видов, происходящих из умеренно теплых районов Юго-Восточной Азии, Сибири и Европы (Тахтаджян, 1987). Типичные местообитания для большинства лилейников - негустые леса, кустарниковые заросли, лесные и пойменные луга (Жизнь ..., 1982; Вяткин, 2003). 
Неприхотливость к условиям произрастания, высокая экологическая пластичность и нетребовательность к почвам сделали лилейник очень популярным в ландшафтном дизайне. В декоративном садоводстве разных стран мира наиболее широко применяются 6 видов этого растения: лилейник оранжевый (Hemerocallis aurantiaca Baker), л. лимонно-желтый (H. citrina Baroni), л. буро-желтый (H. fulva L.), л. желтый (H. flava L. или H. lilio-asphodelus L.), л. Миддендорфа (H. middendorffii Trautv. et Mey), л. малый (H. minor Mill.) (Баканова, 1984). В основном именно эти виды послужили исходными формами для создания современных садовых гибридов (H. hybrida×hort.) (Полетико, Мишенкова, 1967). Сорта лилейника гибридного обладают более продолжительным периодом цветения, чем видовые; наличием ремонтантного, повторного, цветения; крупными цветками разнообразных форм и окрасок, благодаря чему занимают одно из ведущих мест среди многолетников открытого грунта (Химина, 2002). Если видовые лилейники имеют в основном желто-оранжевую и красновато-бурую окраску, то в окраске гибридных присутствуют все цвета и оттенки спектра (Улановская, 2009).

В УНЦ «Ботанический сад» СГУ им. Н. Г. Чернышевского в отделе флоры и растительности произрастает пять образцов лилейников, которые относятся к природной флоре: H. citrina Baroni, $H$. fulva (L.) L., H. lilio-asphodelus L., H. minor Mill, H. middendorfii Trautv. et C. А. Меу. Данные виды - короткокорневищные поликарпики, которые по классификации И. В. Борисовой (1965) являются раннелетнецветущими, длительновегетирующими многолетниками. В отделе интродукции цветочно-декоративных культур коллекция лилейника гибридного насчитывает 54 сорта. Коллекция по своему сортовому составу сформирована таким образом, что в нее вошли гибриды разных групп по плоидности, форме цветка, окраске и срокам цветения.

Целью наших исследований было изучение в климатических условиях города Саратова ритмов развития трех видов: H. citrina Baroni, H. fulva (L.) L., H. lilio-asphodelus L. и 15-ти сортов лилейника гибридного, различающихся по срокам и типу цветения и плоидности: диплоидные формы - 'Americane Revolution', 'Night Beacon', 'Nigrette', 'Theresa Hall', 'Luxury Lice', 'Cara Mia', 'Tejas', 'Prairie Blue Eyes', 'Winnie-The-Pooh', 'Carry Queen', 'Regal Air', 'Date Book'; тетраплоидные формы - 'Sabina Bauer', 'Глория', 'Grand Palase'. Также была проведена интродукционная оценка изученных образцов.

В ходе фенологических наблюдений в период с 2010 по 2018 гг. в УНЦ «Ботанический сад» СГУ г. Саратова были установлены календарные даты основных фаз развития, определены средние значения сроков и продолжительность цветения у образцов. Фенологические наблюдения за коллекционными растениями проводились по общепринятой методике ГБС (Методика фенологических ..., 1976). Под фенологическими фазами понимали внешние проявления сезонных изменений растения. Отмечали следующие фенофазы: начало весеннего отрастания, бутонизация, начало цветения, массовое цветение, конец цветения, конец вегетации. Результаты наблюдений в виде фенодат были переведены в непрерывный ряд чисел (Зайцев, 1978). Для каждой фенофазы рассчитывали среднее арифметическое, среднее квадратическое отклонение, ошибку средней арифметической. Затем средние округлялись и переводились в обычные календарные даты. Ошибки средних арифметических также округлялись до целого числа, умножались на 3 и записывались со знаком \pm рядом со средней арифметической. Таким образом, устанавливалась средняя фенодата (Зайцев, 1978). Полученные данные приводятся в таблице 1.

Интродукционная оценка исследуемых экземпляров была выполнена по критериям оценки интродукции В. Н. Былова и Р. А. Карписоновой (1987) с дополнениями, учитывающими природно-климатические условия юго-востока европейской части России (Шилова и др., 2007). Данная шкала учитывает способность растений к семенному и вегетативному размножению, их общее состояние и продуктивность цветения, устойчивость к вредителям и болезням, состояние после перезимовки и летней засухи. Каждый параметр оценивается по трехбалльной шкале, при этом 1 балл соответствует наихудшим показателям. Оценка производится путем суммирования показателей по всем признакам. По данной шкале малоперспективные к введению в культуру виды имеют суммарную оценку от 6 до 10 баллов, перспективные виды - от 11 до 15 баллов, очень перспективные - от 16 до 18 баллов.

Анализ фенологических наблюдений показал, что изученные образцы видовых и сортовых лилейников различаются по ритму развития. Даты начала весеннего отрастания существенно варьируют по годам. Это связано, в первую очередь, с погодно-климатическими условиями и сроками таяния сне- 
га, а также зависит от биологических особенностей вида. В среднем начало отрастания как видовых, так и сортовых лилейников приходится на первую декаду апреля (табл. 1).

Таблица 1

Средние даты наступления основных фенологических фаз H. citrina, H. fulva, H. lilio-asphodelus и сортов лилейника гибридного в период с 2010 по 2018 гг.

\begin{tabular}{|c|c|c|c|c|c|c|c|}
\hline Название & 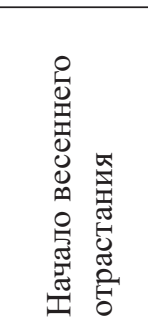 & 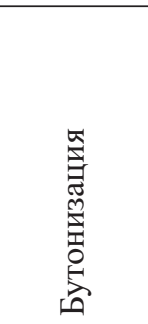 & 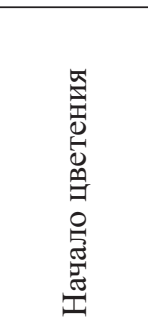 & 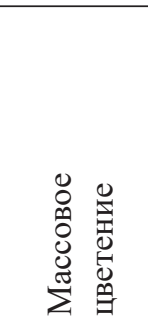 & 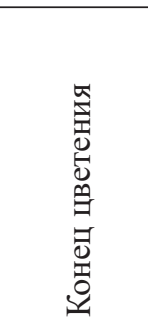 & 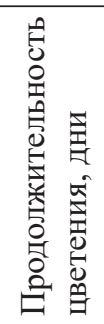 & 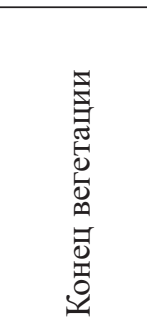 \\
\hline H. lilio-asphodelus & $12.04 \pm 3$ & $18.05 \pm 4$ & $26.05 \pm 2$ & $15.06 \pm 4$ & $23.06 \pm 4$ & $19 \pm 3$ & $21.10 \pm 4$ \\
\hline H. citrina & $13.04 \pm 3$ & $12.05 \pm 3$ & $21.05 \pm 2$ & $03.06 \pm 4$ & $24.06 \pm 4$ & $34 \pm 5$ & $20.10 \pm 4$ \\
\hline H. fulva & $02.04 \pm 4$ & $17.05 \pm 5$ & $26.05 \pm 5$ & $27.05 \pm 5$ & $20.06 \pm 2$ & $23 \pm 6$ & $18.10 \pm 3$ \\
\hline 'Carry Queen' & $09.04 \pm 4$ & $13.06 \pm 7$ & $04.07 \pm 5$ & $11.07 \pm 5$ & $07.08 \pm 4$ & $35 \pm 5$ & $17.11 \pm 3$ \\
\hline 'Date Book' & $07.04 \pm 3$ & $15.06 \pm 5$ & $11.07 \pm 8$ & $16.07 \pm 4$ & $10.08 \pm 4$ & $30 \pm 5$ & $14.11 \pm 3$ \\
\hline 'Regal Air' & $08.04 \pm 4$ & $11.06 \pm 6$ & $24.06 \pm 7$ & $04.07 \pm 5$ & $30.07 \pm 7$ & $36 \pm 6$ & $19.11 \pm 3$ \\
\hline 'Sabina Bauer' & $10.04 \pm 5$ & $02.07 \pm 4$ & $11.07 \pm 4$ & $23.07 \pm 5$ & $05.08 \pm 7$ & $25 \pm 6$ & $19.11 \pm 3$ \\
\hline 'Глория' & $07.04 \pm 3$ & $16.06 \pm 7$ & $08.07 \pm 8$ & $15.07 \pm 4$ & $07.08 \pm 6$ & $30 \pm 7$ & $20.11 \pm 3$ \\
\hline 'Americane Revolution' & $07.04 \pm 3$ & $17.06 \pm 5$ & $06.07 \pm 4$ & $13.07 \pm 4$ & $06.08 \pm 7$ & $31 \pm 5$ & $19.11 \pm 3$ \\
\hline 'Grand Palase' & $09.04 \pm 2$ & $16.06 \pm 4$ & $05.07 \pm 5$ & $10.07 \pm 3$ & $07.08 \pm 8$ & $33 \pm 6$ & $15.11 \pm 3$ \\
\hline 'Nigrette' & $10.04 \pm 3$ & $15.06 \pm 5$ & $09.07 \pm 6$ & $15.07 \pm 4$ & $31.07 \pm 7$ & $22 \pm 7$ & $15.11 \pm 3$ \\
\hline 'Prairie Blue Eyes' & $09.04 \pm 3$ & $18.06 \pm 6$ & $27.06 \pm 6$ & $01.07 \pm 5$ & $01.08 \pm 4$ & $35 \pm 5$ & $15.11 \pm 3$ \\
\hline 'Luxury Lice' & $10.04 \pm 3$ & $19.06 \pm 4$ & $08.07 \pm 6$ & $16.07 \pm 5$ & $31.07 \pm 5$ & $23 \pm 8$ & $19.11 \pm 3$ \\
\hline 'Cara Mia' & $08.04 \pm 3$ & $15.06 \pm 5$ & $26.06 \pm 8$ & $09.07 \pm 5$ & $23.07 \pm 4$ & $27 \pm 6$ & $15.11 \pm 3$ \\
\hline 'Tejas' & $09.04 \pm 4$ & $9.07 \pm 7$ & $22.07 \pm 7$ & $31.07 \pm 5$ & $08.08 \pm 4$ & $17 \pm 8$ & $14.11 \pm 3$ \\
\hline 'Winnie-The-Pooh' & $11.04 \pm 3$ & $14.06 \pm 7$ & $29.06 \pm 6$ & $10.07 \pm 5$ & $09.08 \pm 7$ & $41 \pm 4$ & $15.11 \pm 3$ \\
\hline 'Night Beacon' & $10.04 \pm 4$ & $16.06 \pm 4$ & $09.07 \pm 6$ & $14.07 \pm 4$ & $04.08 \pm 4$ & $26 \pm 6$ & $19.11 \pm 3$ \\
\hline 'Theresa Hall' & $07.04 \pm 3$ & $18.06 \pm 5$ & $13.07 \pm 6$ & $19.07 \pm 4$ & $08.08 \pm 5$ & $26 \pm 8$ & $15.11 \pm 3$ \\
\hline
\end{tabular}

Сроки начала цветения и его продолжительность также являются изменчивым фенологическим признаком, зависящим от индивидуальных биологических особенностей сорта, почвенно-климатических условий текущего и предшествующего годов, накопления определенной суммы температур, необходимой для зацветания. В связи с этим даты начала цветения различных сортов в разные годы могут сдвигаться в ту или другую сторону.

Изученные сорта лилейников по времени зацветания группировались на зацветающие в конце июня (24.06-29.06) и зацветающие в первой декаде июля (4.07-13.07) (табл. 1). Только сорт 'Тејаs' начинал цвести в третьей декаде июля. Продолжительность данной фенофазы у основной массы сортов раннего, раннесреднего и среднего срока цветения в среднем составила 22-35 дней. Самый короткий период цветения был у сорта 'Tejas', более длительный - у сорта 'Winnie-The-Pooh'. Длительность цветения среднепоздних сортов 'Night Beacon' и 'Theresa Hall' продолжалась 26 дней. Общий период цветения сортовых лилейников в разные годы составил от 17-ти до 41 дня. Повторное цветение у ремонтантных сортов 'Date Book', 'Theresa Hall', 'Глория', 'Sabina Bauer' проявлялось нестабильно и выражалось в том, что в отдельные годы на пике своего цветения у данных сортов начинались выбрасываться новые цветочные стрелки. Начало цветения видовых лилейников приходилось на третью декаду мая. Период цветения H. citrina в среднем составил 34 дня, у H. fulva - 23 дня, а у H. lilio-asphodelus цветение было непродолжительным - 19 дней. Как правило, период массового цветения у видовых лилейников приходится на первую половину июня. Вторичное цветение у видовых форм не отмечалось. Так как про- 
должительность цветения у сортов и видов растянуты во времени, их можно включать в ландшафтные монокомпозиции непрерывного цветения, которые в настоящий момент набирают популярность (рис.).

В результате проведенной интродукционной оценки видно, что изученные виды лилейника являются перспективными для введения в культуру (табл. 2). Они формируют семена и способны к семенному возобновлению. На коллекционном участке отмечался самосев, причем наиболее обильный у H. lilio-asphodelus. В то же время вегетативно самостоятельно не размножаются. Все исследованные нами образцы морозо- и засухоустойчивы, практически не повреждаются вредителями. Однако после схода снега куртины требуют удаления ветоши для предотвращения выпревания.

Итоги интродукционной оценки сортов лилейника гибридного показали, что все изученные сорта, за исключением сорта 'Date Book', можно отнести к очень перспективным (табл. 2). В отличие от видовых форм, у всех изученных сортов лилейника гибридного отмечено хорошее естественное вегетативное размножение. Тогда как по признаку «способность к семенному размножению» у сортов 'Date Book', 'Глория', 'Grand Palase', 'Theresa Hall' образование семян отсутствовало, остальные сорта имели среднюю реальную семенную продуктивность (табл. 2). Общее состояние растений и продуктивность их цветения отражают приспособленность растения в условиях культуры и их декоративность. По этому признаку все сорта имели мощные, регулярно и обильно цветущие кусты. В годы исследований не было обнаружено повреждений листьев и цветов болезнями и вредителями, как у сортовых, так и у видовых образцов. Все изученные сорта показали себя морозо- и засухоустойчивыми.

Проведенное изучение показало, что H. citrina, H. fulva, H. lilio-asphodelus и 15 сортовых форм лилейника гибридного устойчивы в культуре, так как в условиях г. Саратова растения зимостойки, засухоустойчивы, невосприимчивы к болезням и вредителям, отличаются декоративностью цветения. Сорта лилейника гибридного адаптировались и в течение ряда лет успешно произрастают, не потеряв своих сортовых особенностей. Оценка успешности интродукции показала, что изученные виды и сорта лилейников оказались очень перспективными для введения в культуру и могут быть рекомендованы для озеленения в условиях г. Саратова. Использование изученных видов и сортов лилейника разных сроков цветения расширяют возможности их применения в ландшафтном дизайне и создания композиций непрерывного цветения.

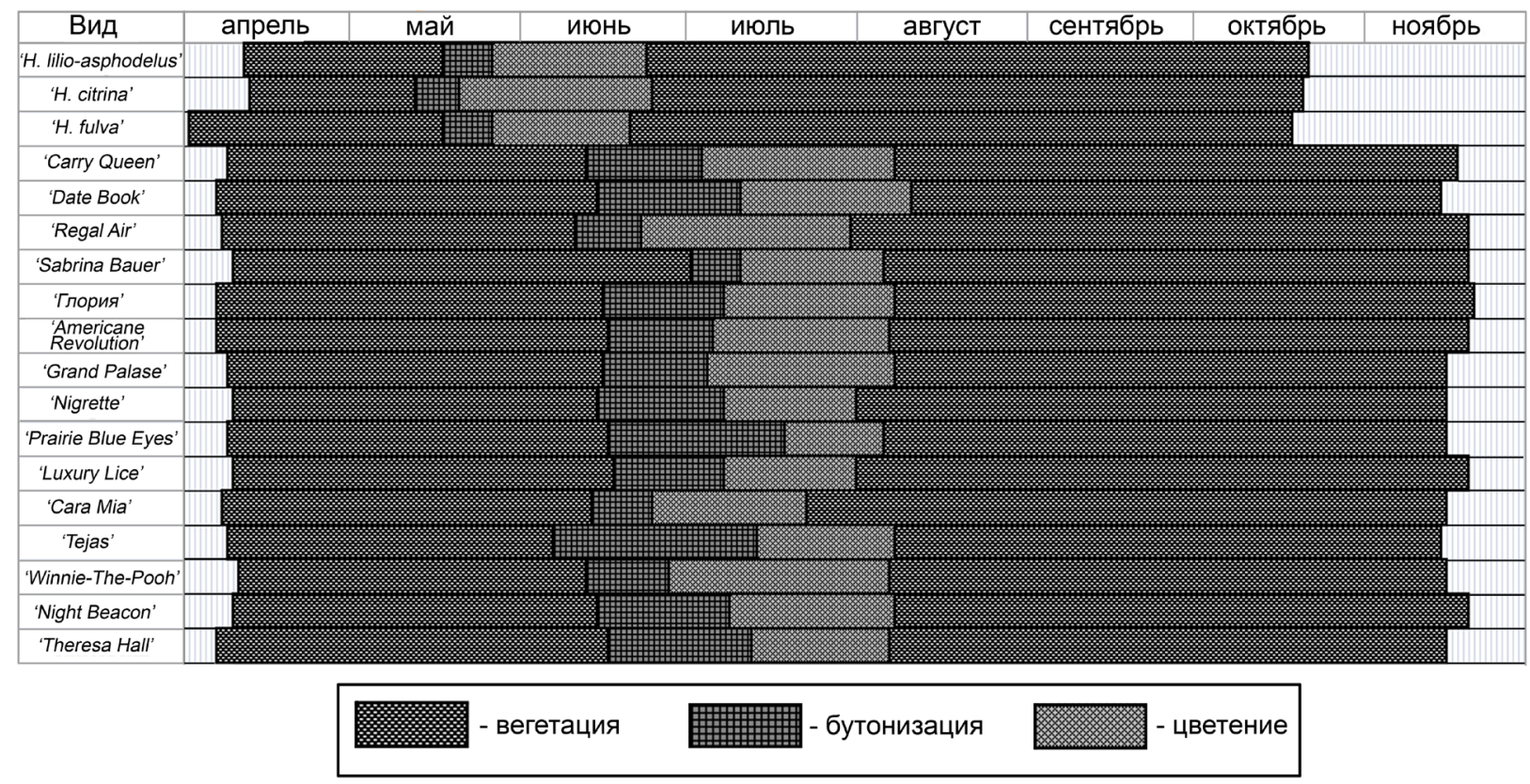

Рис. Фенологические спектры H. citrina, H. fulva, H. lilio-asphodelus и сортов лилейника гибридного в условиях г. Саратова. 
Оценка успешности интродукции исследуемых образцов рода Hemerocallis L.

\begin{tabular}{|c|c|c|c|c|c|c|c|}
\hline Название & 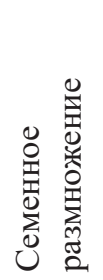 & 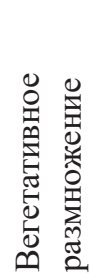 & 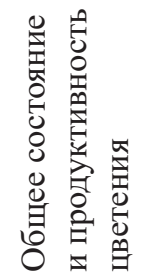 & 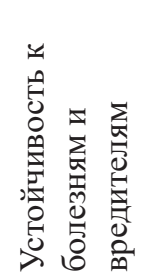 & 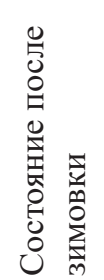 & 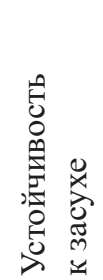 & 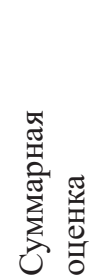 \\
\hline H. lilio-asphodelus & 3 & 2 & 3 & 3 & 3 & 3 & 17 \\
\hline H. citrina & 2 & 2 & 3 & 3 & 3 & 3 & 16 \\
\hline H. fulva & 3 & 2 & 3 & 3 & 3 & 3 & 17 \\
\hline 'Carry Queen' & 2 & 3 & 3 & 3 & 3 & 3 & 17 \\
\hline 'Date Book' & 1 & 3 & 2 & 3 & 3 & 3 & 15 \\
\hline 'Regal Air' & 2 & 3 & 3 & 3 & 3 & 3 & 17 \\
\hline 'Sabina Bauer' & 3 & 3 & 3 & 3 & 3 & 3 & 18 \\
\hline 'Глория' & 1 & 3 & 3 & 3 & 3 & 3 & 16 \\
\hline 'Americane Revolution' & 3 & 3 & 3 & 3 & 3 & 3 & 18 \\
\hline 'Grand Palase' & 1 & 3 & 3 & 3 & 3 & 3 & 17 \\
\hline 'Nigrette' & 2 & 3 & 3 & 3 & 3 & 3 & 17 \\
\hline 'Prairie Blue Eyes' & 3 & 3 & 3 & 3 & 3 & 3 & 18 \\
\hline 'Luxury Lice' & 3 & 3 & 3 & 3 & 3 & 3 & 18 \\
\hline 'Cara Mia' & 2 & 3 & 3 & 3 & 3 & 3 & 17 \\
\hline 'Tejas' & 2 & 3 & 3 & 3 & 3 & 3 & 17 \\
\hline 'Winnie-The-Pooh' & 2 & 3 & 3 & 3 & 3 & 3 & 17 \\
\hline 'Night Beacon' & 2 & 3 & 3 & 3 & 3 & 3 & 17 \\
\hline 'Theresa Hall' & 1 & 3 & 3 & 3 & 3 & 3 & 16 \\
\hline
\end{tabular}

\section{ЛИТЕРАТУРА}

Баканова В. В. Цветочно-декоративные многолетники открытого грунта. - Киев: Наукова думка, 1984. - 152 с.

Борисова И. В. Ритмы развития степных растений и зональных типов степной растительности Центрального Казахстана // Труды Ботанического института им. Комарова. Геоботаника. - М., Л.: Наука, 1965. - Сер. 3 , вып. 17. - C. 64-99.

Былов В. Н., Карписонова Р. А. Принципы создания и изучения коллекции малораспространенных декоративных многолетников // Бюл. ГБС, 1987. - № 107. - С. 77-82.

Вяткин А. И. Красодневы в Сибири. - Новосибирск: Дачный мир, 2003. - 32 с.

Жизнь растений. Цветковые растения / под ред. А. Л. Тахтаджяна. - М.: Просвещение, 1982. - Т.6. - 543 с.

Зайцев Г. Н. Фенология травянистых многолетников. - М.: Наука, 1978. - 50 с.

Методика фенологических наблюдений в ботанических садах СССР. - М.: Изд-во АН СССР, 1976. - 27 с .

Полетико О. М., Мишенкова А. П. Декоративные травянистые растения открытого грунта. - Л.: Наука, 1967. - $207 \mathrm{c}$.

Тахтаджсян А. Л. Система магнолиофитов. - Л.: Наука, 1987. - 439 с.

Улановская И. В. О коллекции лилейника в Никитском ботаническом саду // Бюл. Никитского ботанического сада, 2009. - Вып. 99. - С 21-23.

Химина Н. И. Лилейники. - М.: Издательский дом МСП, 2002. - 208 с.

Шилова И. В., Панин А. В., Кашин А. С., Машурчак Н. В., Бердников А. В., Соловьёва М. В. Методы интродукционного изучения лекарственных растений: учеб.-метод. пособие для студентов биол. фак. - Саратов: ИЦ «Наука», 2007. -45 с. 